\title{
O MÉTODO GROUNDED THEORY NAS PESQUISAS EM EDUCAÇÃO SEXUAL
}

BORTOLOZZI, Ana Cláudia

SILVA, Claudionor Renato da

\begin{abstract}
Resumo
Grounded Theory (GT) é um método pouco utilizado na área da educação sexual e também na área da educação. O método se propõe formular teorizações que emergem de dados da realidade empírica. Este estudo objetiva apresentar o GT e sua aplicabilidade na área da educação sexual, a partir de uma pesquisa de doutoramento em sexualidade infantil, gerando uma teorização a partir de dados documentais. Os resultados indicam três vertentes de teorização: a do cotidiano escolar nas relações entre pais, crianças, gestão escolar e professores; a psicanálise - de Freud até a contemporaneidade; temáticas sociais e de políticas públicas sobre a infância e a criança. A teorização,numa cientificidade em sexualidade infantil abre uma proposta de pesquisas na área da educação sexual voltada à teorizações que podem vir a se tornar teorias e, assim, fazer avançar a produção de conhecimento na área da educação sexual.
\end{abstract}

Palavras-chave: Grounded Theory. Pesquisa em Educação. Educação Sexual.

\section{THE METHOD GROUNDED THEORY IN RESEARCH ON SEX EDUCATION}

\begin{abstract}
Grounded Theory (GT) is a methodrarelyused in thefieldof sexual educationandalso in education. The methodisproposedtoformulatetheoriesthat emerge fromtheempirical reality data. Thisstudyaimstopresentthe GT and its applicability in thefieldof sex educationfrom a doctoralresearchonchildhoodsexuality, generatingtheorizingfromdocumentaryevidence. The resultsindicatethreestrandsoftheorizing: theschoolroutine in relationshipsbetweenparents, children, school management andteachers; psychoanalysis - Freud tocontemporary; social andpublic policies onchildhoodandchildthemes. Theorizing, a scientific in infantilesexuality opens a proposal for research in sex educationaimedattheorizingthatmaybecometheoriesandthusadvancingtheproduction ofknowledge in thespecificarea sex education.
\end{abstract}

Keywords: GroundedTheory. Research in Education. Sex education.

\section{Introdução}

A Grounded Theory (GT) não é um método utilizado com frequência nas pesquisas em educação sexual, tão pouco na área da educação. Uma hipótese para isto, talvez, seja o fato de que a pedagogia e outras licenciaturas sejam 
consideradas no âmbito de uma ciência da prática social ou ciência da práxis (Franco, 2008; Ghedin e Franco, 2011).

Agatha Vianna no artigo "Panorama da pesquisa universitária no Brasil: angústias e proposições", publicado aqui mesmo, na Revista do Programa de PósGraduação em Educação - UNESC - (VIANNA, 2015) problematiza a questão da produção de conhecimento no campo educacional quando se valoriza a quantidade em vez da qualidade produzindo uma ciência e uma pesquisa em educação nas palavras da autora - "massificada". Tal massificação, indica-nos a autora,implica, fundamentalmente, na importância e na urgência de "[...] uma análise da qualidade da pesquisa [...] no campo educacional brasileiro.

$\mathrm{E}$, neste sentido, muito de toda produção do conhecimento educacional não chega à constituição de uma teoria ou um modelo teórico interpretativo ou ainda, uma teorização. Tais constituições, teórica ou modelar, estariam fora das prioridades da área educacional, pela valorização da pesquisa qualitativa e o afastamento de uma proposta quantitativa e também epistemológica, no sentido da teoria pedagógica e como bem apontou Vianna (2015) há uma superficialidade nas pesquisas sugerindo que seus resultados sejam questionáveis, justamente, porque o método e o próprio resultado das pesquisas seguirem a lógica da quantidade e da "pressa".

A Grounded Theory no campo educacional tem a proposição, por umapráxis sócio científica em educação (Franco, 2008; Ghedin; Franco, 2011; Pimenta, 2012) gerando (novas) teoria(s) e/ou (novos) modelos de sistematização e interpretação voltados à prática educacional, seguidos por um rigor, por um dispêndio de energia e seriedade na condução da pesquisa no campo educacional.

Pode-se evidenciar uma problemática para este estudo a partir da seguinte questão geral: o que é e como se configuraria uma pesquisa no método da GT, gerando produção de conhecimento na área da educação sexual?

O objetivo para se responder à pergunta da pesquisa segue a ideia geral de apresentar a GT no campo da educação sexual. Nesta apresentação, objetiva-se ainda, identificar os caminhos da instituição do método que podem ser construídos visando uma teorização na produção de conhecimento da área da educação sexual, uma área já com amplo desenvolvimento conceitual e metodológico. Neste artigo, 
demonstra-se uma teorização em uma subárea da educação sexual: a sexualidade infantil. Pretende-se apresentar a GT enquanto método de pesquisa e um exemplo de teorização em sexualidade infantil, a partir da utilização direta e completa do método - trata-se de uma pesquisa de doutorado concluída.

Nas considerações finais, pretende-se mostrar alguns itens de validação, de limitação e de legitimidade nas pesquisas em educação sexual com a utilização da GT e que, de forma ampla, responde ao problema da pesquisa aqui formulado para este artigo.

Considera-se o método de estruturação deste trabalho como bibliográfico, segundo Sampieri; Collado; Lucio (2006). Para estes autores, a pesquisa bibliográfica

consiste em identificar, obter e consultar a bibliografia e outros materiais que sejam úteis para os objetivos de estudo, do qual se deve extrair e recompilar a informação relevante e necessária sobre o nosso problema de pesquisa (SAMPIERI; COLLADO; LÚCIO, 2006, p.54).

Assim, o direcionamento do presente artigo se inicia e percorre até às considerações finais a indicação da problemática desenvolvida em que as respostas encontram-se no interior do próprio método, dando originalidade à teorização que se pretende formatar em pesquisas que se utilizam da Grounded Theory.

\section{O que é e como se dá o método GT?}

Kathy Charmaz representa, atualmente, a vertente Construtivista da GT; vertente esta que aceita o múltiplo e o plural, no olhar sobre a realidade observada, investigada, ou seja, fatos e significados destes fatos podem ser construídos pelo pesquisado e pelo pesquisador, na construção, junto aos dados, da teoria emergente.

Que procedimentos propõe Charmaz (2009) para uma pesquisa em GT?

1. Definição do objetivo(s) e da pergunta (ampla) da pesquisa.

2. Codificação inicial (coleta de dados).

3. Memorandos iniciais.

4. Nova coleta de dados, mas uma coleta mais específica para saturação dos dados, denominado por Charmaz de "codificação focalizada". 
5. Memorandos avançados.

6. Amostragem teórica, buscando novos dados, para certificação de que, de fato, os dados foram saturados.

7. Organização de categorias e conceitos teóricos. Ao mesmo tempo, redação de memorandos com refinamento das categorias e conceitos.

8. Integração de memorandos (prévia organização da teorização).

9. Redação do primeiro rascunho da teorização.

10. Redação da teorização.

Antes de comentar as etapas do método, acima apresentadas, é importante já se definir o que é teorização ou o que significa, no método, teorizar.Charmaz (2009) afirma que a teorização mais importante que uma teoria, ou seja, a interpretação da realidade investigada: “(..) a teorização é uma prática, a qual requer a atividade prática de dedicar-se ao mundo e de construir compreensões abstratas sobre ele e dentro dele (p.176)".

E prossegue:

Teorizar significa parar, considerar e repensar de uma nova maneira. Suspendemos o fluxo da experiência estudada e a isolamos. Para alcançarmos a sensibilidade teórica, observamos a vida estudada a partir de múltiplas perspectivas privilegiadas, fazemos comparações, seguimos pistas e exploramos ideias (CHARMAZ, 2009, p. 185).

Teorizar, diferentemente de "teoria" - esta última seria um degrau acima da abstração científica, segundo Silva (2015) - é, portanto, a construção de um pensamento lógico e encadeado que nasce do olhar e da abstração aprofundada do pesquisador, ao mesmo tempo, descritiva e analítica que encaminha primeiros insights para uma (futura) teoria. Será retomada esta discussão ao longo do artigo.

Mas o que é e como deve ser e, no que se constitui uma teorização na GT? $\mathrm{Na}$ abordagem construtivista de Charmaz (2009) toda teorização construída sob o método da GT deve atingir aos seguintes objetivos:

- Desenvolver as propriedades de cada categoria construída e demonstrar como elas se articulam.

- Identificar os atores que participam nas fontes de dados iniciais: suas falas, seus posicionamentos em seus respectivos contextos. 
- Sugerir e explicitar a teoria constituída no encadeamento das propriedades categoriais e na identificação dos atores.

Teorização na abordagem construtivista é compreensiva. Nunca explicativa. A realidade é sempre múltipla e emergente; indeterminada; nunca vista isoladamente, mas associados sempre os fatos e os valores; a verdade é sempre provisória e a vida social um processo (CHARMAZ, 2009).

Outro ponto importante: a teoria é sempre retórica, ou seja

\begin{abstract}
Um teórico tenta convencer os leitores de que determinadas conclusões derivam de um conjunto de premissas [...]. Assim, as teorias apresentam argumentos sobre o mundo e as relações existentes dentro dele, apesar de muitas vezes isso aparecer depurado do seu contexto e reduzido a enunciados aparentemente neutros. [...] As teorias provocam insights esclarecedores e dão sentido às reflexões obscuras e aos problemas complicados. As ideias se ajustam. Tornam-se evidentes os fenômenos e as relações existentes entre eles que, anteriormente, você pôde apenas sentir. Entretanto, as teorias podem ir além. Uma teoria pode alterar o seu ponto de vista e modificar a sua consciência. Por meio dela, você consegue ver o mundo de um ângulo diferente e gerar novos significados por meio dele. As teorias têm uma lógica interna e, de certa forma, aglutinam-se em contornos coerentes (CHARMAZ, 2009, p. 176).
\end{abstract}

Retornando às etapas do método, Kathy Charmaz denomina a coleta de dados inicial como "dados relevantes", à medida que se constituem o "coração da pesquisa", podendo ser observação, entrevista ou documentos (análise textual).

A fonte dos dados em textos arquivados, acessados, constituem o que Charmaz denomina de "textos existentes", são"[...] discussões da internet e os banco de dados de materiais qualitativos anteriores. Quando os pesquisadores utilizam textos existentes, os seus leitores podem acreditar que esses textos refletem a realidade (CHARMAZ, 2009, p. 61)".

Charmaz não descarta as limitações dos textos existentes como dados ao pesquisador que pretende produzir teorização a partir do método da GT. Por isso, alerta:

$\mathrm{Na}$ medida do possível, precisamos situar os textos dentro dos seus contextos. Nos dias de hoje, a pesquisa na internet oferece oportunidades infinitas para a análise textual, além de impor enormes questões metodológicas, sendo a principal delas relacionada aos textos sem contextos. De onde vêm os dados? Quem participou da construção deles? Qual era a intenção dos autores? Será que os participantes forneceram informação suficiente para fazermos uma interpretação plausível? E será que temos conhecimento suficiente das esferas de vida relevantes para 
lermos as suas palavras com alguma compreensão? (CHARMAZ, 2009, p. $63)$.

Ainda sobre os dados de fontes documentais Kathy Charmaz, afirma:

[...] as pessoas constroem os dados - quer os pesquisadores construam dados de primeira mão, por meio de entrevistas ou notas de campo, ou reúnam textos e informações a partir de outras fontes como documentos históricos, registros governamentais ou informações organizacionais compiladas para discussão privada ou disseminação pública. Podemos considerar como fatos os dados provenientes desses documentos, registros e censos; contudo, estes foram construídos por indivíduos (CHARMAZ, 2009, p.33).

Nesta etapa inicial de acesso aos textos e primeiras leituras tem-se a produção de conceitos provisórios e algumas sentenças ou categorias, de modo que o pesquisador deve ter em mente, sempre, as seguintes questões, para, de fato, serem levantados dados relevantes:

A coleta de dados relevantes fornecerá a você material sólido para a construção de uma análise significativa. Os dados relevantes são detalhados, focados e completos. Eles revelam as opiniões, os sentimentos, as intenções e as ações dos participantes, bem como os contextos e as estruturas de suas vidas. A obtenção de dados relevantes significa uma descrição "densa" [...] (CHARMAZ, 2009. p. 30).

Uma particularidade da GT, que se vê nesta primeira etapa, a da codificação aberta dos dados é que o pesquisador tem a liberdade de orientar, de acordo com os dados que estão sendo levantados, novos percursos de configuração do próprio método. "Podemos acrescentar novas peças ao quebra-cabeça da pesquisa ou criarmos quebra-cabeças inteiramente novos - enquanto coletamos os dados - e, isso pode ocorrer até mesmo posteriormente, durante a análise (CHARMAZ, 2009, p. 31)".

A organização de conceitos para formatação da teoria é uma exigência na fase de codificação dos dados. Charmaz se baseia em Herbert Blumer - conceitos sensibilizadores - como forma de organização das codificações que se fazem ao longo da geração da teorização. Conceitos são sempre pontos de partida e não devem nunca ser limitadores da produção do pesquisador. "Sendo assim, desenvolvemos conceitos específicos pelo estudo dos dados e pelo exame das nossas ideias por meio dos níveis sucessivos de análise (CHARMAZ, 2009, p. 34)".

Criar Educação, Criciúma, v. 6, ํo1, janeiro/junho 2017.- PPGE - UNESC 
Uma dica para a codificação dada por Charmaz:

- Permanecer sempre aberto à invenções e produções a partir das produções.

- Nunca se afastar os dados, os dados são tudo numa pesquisa em GT.

- Os códigos elaborados ou categorias analíticas devem ser curas, simples e precisas com características de ação.

- Na codificação, é também essencial, a comparação com os dados.

- O pesquisador deve sempre "caminhar", "transitar" entre os dados.

A codificação pode ser "palavra a palavra" (mais aprofundada e prende o pesquisador que analisa dados documentais a dar um toque de originalidade para manter a realidade escrita, sem alterar a perspectiva dos participantes que informa os fatos), "linha a linha" (que também não impede uma maior "labuta" ao pesquisador consiste numa maior amplitude de interpretação dos dados; linha a linha, permite uma maior ideia da realidade do que palavra por palavra, o que implica uma maior possibilidade de "invenção" de categorias e conceitos por parte do pesquisador).

$\mathrm{Na}$ codificação "linha a linha" a preocupação do pesquisador em GT deve estar centrada nas seguintes perguntas:

- Qual(is) processo(s) está(ão) em questão aqui? Como posso definílo(s)?

- Como este processo se desenvolve?

- Como age (agem) o(s) participante(s) de pesquisa quando envolvido(s) neste processo?

- $\quad \mathrm{O}$ que o(s) participantes(s) de pesquisa declara(declaram) pensar e sentir quando envolvido(s) neste processo? O que poderia indicar o(s) seu(s) comportamento(s))?

- Quando, por que e como o processo se modifica?

- $\quad$ Quais são as consequências do processo? (CHARMAZ, 2009, p. 79).

$\mathrm{Na}$ codificação "linha a linha" a possibilidade de enriquecimento das categorias e conceitos se tornam mais ricas.

Dentre as muitas contribuições da codificação inicial está a percepção, desde o início, da formulação da teoria e da formulação dos temas da área em estudo, que 
ora necessitam de maior aprofundamento ou que se abrem como categorias ainda emergentes ou necessárias.

E de que se trata a codificação focalizada?

A codificação focalizada significa utilizar os códigos anteriores mais significativos e/ou frequentes par analisar minuciosamente grandes montantes de dados. A codificação focalizada exige a tomada de decisão sobre as quais os códigos iniciais permitem uma compreensão analítica melhor para categorizar os seus dados de forma incisiva e completa (CHARMAZ, 2009, p. 87).

Nesta etapa da codificação, o envolvimento do pesquisador é muito mais exigido, pois a criação da teorização, do novo, depende deste foco em pormenores que podem ser decisivos para a teorização em construção. É um momento de criação de categorias e conceitos, com idas e vindas aos dados.

Charmaz apresenta o terceiro tipo de codificação da GT, a axial, em que, as categorias são relacionadas umas com as outras e também se faz a identificação das particularidades e especificidades de cada categoria. Na codificação axial se classifica, sintetiza e organiza "[...] grandes montantes de dados [...] (Charmaz, 2009, p. 91)" e tais dados são reagrupados de forma diferente, ou de forma mais refinada, para facilitar os memorandos avançados, bem como o relatório final que vai gerar a teorização.

A redação de memorandos é uma parte fundamental na organização proposta pelo método. Os memorandos são escritos sobre o que é encontrado nas codificações. A partir dos memorandos é que se transformam as categorias provisórias em conceitos também ainda também provisórios, mas muito próximos da teorização e da estrutura do relatório final.

Os memorandos são escritos durante todo o processo de construção da teoria, pelo método da GT. Os memorandos são embriões da teorização, uma vez que, durante a codificação, seja aberta, seja a focalizada ou ainda a axial, a pesquisa nos permite ir "induzindo" a formulação da teorização.É o momento dos insights, de abstrações, da criação, da originalidade. Então, é claro, que releituras e revisitas aos dados categorizados e previamente elaborados são necessários neste momento da produção de memorandos. O memorando vai aos poucos dando vida à teorização.Os Memorandos, ademais, permitem o fator comparativo nos dados. 
Talvez seja a melhor oportunidade ou momento, proposto pelo método, para se estabelecer comparações, interligações entre aquilo que será configurado como central na produção da teorização.

Charmaz (2009) propõe Memorandos Iniciais e Memorandos Avançados. Os primeiros são aqueles em que se organizam os primeiros enunciados a partir dos dados documentais. Estas categorias ou primeiros conceitos tem um papel duplo: 0 primeiro é a sistematização dos dados, o segundo é servir de base para a codificação focalizada e amostragem teórica, bem como ao refinamento dos dados pelos memorandos avançados.

Os Memorandos, enfim, elevam as categorias focais à conceitos. E como isto acontece? À medida que os memorandos são pensados, sempre como forma de produção textual de uma categoria que se pretende ser conceitual e, depois, teórica, em que o pesquisador tem que ter uma boa "carga" de imaginatividade, pois terá que inovar, sem permitir que se percam as características das categorias enunciadas a priori e, desta forma, mostrar não somente como está configurada, mas também o percurso histórico que geraram a configuração atual. A parte mais complexa do memorando é o aspecto comparativo das diversas situações ou momentos que alguns elementos categorias se apresentam e a partir destas comparações interligar dados que uma vez afunilados se formatam numa proposta teórica concisa.

Os memorandos avançados podem também serem a articulação dos memorandos iniciais, de forma a integrá-lo para o embrião da teorização emergente.

A próxima etapa, a amostragem teórica é o momento da saturação dos dados que se efetiva na busca de mais dados. Mas, agora, concentrado nas categorias mais centrais. A etapa marca também o refinamento dos dados organizados nos dados documentais relevantes que são as bases da teorização emergente, segundo Charmaz.

$\mathrm{Na}$ amostragem teórica tentamos identificar as propriedades das categorias que foram organizadas na codificação aberta e que já aparecem como ideias embrionárias (emergentes) nos memorandos iniciais. Sente-se o momento de parar, portanto, de "saturar" os dados quando "[...] a coleta de dados novos não mais 
desperta novos insights teóricos, nem revela propriedades novas dessas categorias teóricas centrais (CHARMAZ, 2009, p. 157)".

Saturam-se os dados, ao mesmo tempo, em que as categorias conceituais elaboradas se consolidam ou se vão consolidando nas codificações e na etapa da amostragem teórica.

Concordamos com Charmaz (2009) para quem a GT pode contribuir para o avanço do conhecimento científico, transformar a prática e a realidade social. Para a autora:

\begin{abstract}
Uma sólida combinação de originalidade e credibilidade aumenta a ressonância, a utilidade e o valor subsequente da contribuição. A hipótese de fazer uma contribuição acadêmica requer um estudo cauteloso da literatura relevante, inclusive aquelas que ultrapassam os limites disciplinares, e um posicionamento claro da sua teoria fundamentada ( $p$. 245).
\end{abstract}

Neste sentido, estamos encontrando consonância com autores da área da pedagogia, sobre a possibilidade real de que a educação se configura na transformação social, pela práxis (Franco, 2008; Ghedin e Franco, 2011 e Pimenta, 2012). São acrescentados aqui também, autores da área da educação sexual que a partir do conceito de "emancipação" também apostam, que o tema da sexualidade, na grande área da educação sexual, deve pautar-se no aspecto da transformação da realidade e da aplicabilidade de uma educação sexual escolar que tenha como norte a formação cidadã, crítica, como apontam Maia; Ribeiro (2011) e Clarke (1998; 2003; 2005).

A redação da teorização em formato de relatório é outra particularidade do método em que os memorandos tomam aprofundamentos que são intrínsecos a quase tudo o que se produziu ao longo da pesquisa, seguindo o método, mas também - e só agora - o pesquisador pode adicionar literaturas outras e pesquisas outras, pois os dados e as interpretações construídas pelo método já não sofrem mais nenhuma "influência" externa, conservando a originalidade da produção a partir dos dados (CHARMAZ, 2009; TAROZZI, 2011).

A etapa da avaliação da GT, portanto, da pesquisa, difere do modelo das "considerações finais" de pesquisas dedutivas. Esta particularidade do método é fundamental para a leitura de uma pesquisa no método da GT, gerando teorizações.

Criar Educação, Criciúma, v. 6, ำ1, janeiro/junho 2017.- PPGE - UNESC 
A avaliação da pesquisa deve responder a quatro elementos fundantes e fundadores, segundo Charmaz (2009): credibilidade, originalidade, ressonância e utilidade. Em resumo, esta avaliação deve permitir a validação da pesquisa teorizada, principalmente no que se refere ao avanço da produção de conhecimento da área em estudo, indicando, inclusive, limitações, lacunas e projetando campos de investigação futuros, além da aplicabilidade da teorização na realidade.

\section{Um breve exemplo de aplicação do método: uma teorização em sexualidade infantil na grande área da educação sexual}

Os estudos sobre a sexualidade infantil vêm, cada vez mais, sendo foco das pesquisas nos espaços escolares, seja pela vivência dos professores (as) diante das manifestações de sexualidade das crianças e adolescentes, na educação infantil e no ensino fundamental, sejam pela negação, por parte dos atores escolares e mesmo de alguns pais, desta sexualidade aflorada, real, impregnada de vida e de prazer e intimamente ligada às vivências infantis cheia de curiosidades de si, de seu corpo, do outro mais próximo e do seu entorno maior, sejam este entorno, outras crianças, sejam os adultos com quem convive ou vê cotidianamente.

A negação dos corpos e a consideração de que as crianças são assexuadas não são muito diferentes dos tempos de Freud em seus Três Ensaios sobre Sexualidade quando chama a atenção de médicos, professores e pais, sobre a sexualidade dos pequenos (as).

A estranheza e a negação ainda são as mesmas em pleno século XXI em que as pessoas não se emanciparam sexualmente, embora os movimentos sociais tenham alcançado legitimidade na sociedade e no Estado brasileiro, este último, mesmo com as pressões das religiões e outros setores mais conservadores que vem aos poucos organizando políticas neste sentido da emancipação sexual dos indivíduos e da coletividade, obviamente não sem a resistência de grupos conservadores religiosos, por exemplo, com o discurso da "ideologia de gênero".

É neste enfoque, o da sexualidade infantil, especificamente, o espaço escolar e seus atores, que com o método da Grounded Theory, se origina uma teorização que sistematiza e interpreta a sexualidade infantil no campo educacional, na área da educação sexual. 


\section{Sobre a pesquisa}

Optou-se, nesta pesquisa de doutoramento, pela pesquisa documental, seguindo a vertente construtivista de Kathy Charmaz. Assim, a partir do Google Acadêmico foram localizados os trabalhos referentes ao descritor "sexualidade infantil" publicados de 2004 a 2014.

Num primeiro momento da coleta de dados (Coleta de Dados I) foram elencados 60 trabalhos, sendo, cinco (5) por cada ano, de 2004 a 2014, exceto o ano de 2014, em que, para aprofundamento dos dados, organizou-se 10 trabalhos, como fonte para a codificação aberta.

Destes trabalhos, é muito representativa a (1) a realidade da sexualidade infantil na escola e como ela é tratada pelos atores desta (crianças, professores, gestores e pais); (2) referências específicas à psicanálise, de Sigmund Freud à contemporaneidade e (3) estudos apontando políticas de proteção à infância, concernentes à violência e ao abuso sexuais.

Após esta coleta de dados inicial foi realizada uma segunda coleta sob o mesmo descritor - "sexualidade infantil" - focando trabalhos compreendidos entre 0 ano de 2010 e 2014, no Banco de Teses da CAPES, totalizando 33 trabalhos, para fins de saturação dos dados, temas e categorias vinculadas às primeiras sentenças categoriais codificadas (SCC). O que são as sentenças categorias codificadas? São sentenças curtas, elaboradas pelo autor, a partir da leitura, na íntegra dos textos elencados nos dados, com destaque a fragmentos dos textos (dados). Tanto os dados iniciais da primeira coleta, quando os da segunda coleta tiveram a construção, texto a texto, de sentenças categorias codificadas (SCC) - Quadro 1.

Quadro 1. Exemplo de sentenças categoriais codificadas.

\begin{tabular}{|l|l|}
\hline CODIFICAÇÃO & \multicolumn{1}{|c|}{ SCC } \\
\hline 1.1 & $\begin{array}{l}\text { A sexualidade infantil evidenciada na escola da infância: } \\
\text { manifestações e dúvidas. }\end{array}$ \\
\hline 1.2 & Freud defende a sexualidade da criança. \\
\hline 1.3 & $\begin{array}{l}\text { Algumas respostas dos professores quando se trata de } \\
\text { sexualidade infantil, são, sem nenhuma base de conhecimento } \\
\text { em educação sexual... Simplesmente, senso comum e com }\end{array}$ \\
\hline
\end{tabular}

Criar Educação, Criciúma, v. 6, ํ1, janeiro/junho 2017.- PPGE - UNESC 

religiosa.

Fonte: Silva (2015, p. 113).

A codificação indica o fragmento do texto em que a SCC foi elaborada. O fragmento, bem como a referência bibliográfica está organizado no Apêndice da tese (SILVA, 2015).

Destes 33 trabalhos apenas 19 tomaram parte na pesquisa, os demais, totalizando 14 trabalhos, foram excluídos da amostragem, após leitura na íntegra dos resumos e textos completos - aqueles acessíveis - pois, não se direcionavam efetivamente ao tema da sexualidade infantil e a pergunta central da pesquisa: "O que está acontecendo aqui?", sob a ótica clássica da GT.

De qualquer forma os dados da amostragem teórica não sofreram nenhum tipo de interferência por estas questões acima mencionadas, pois não se trata de entender a "saturação de dados" como repetição ou quantificação de elementos ou propriedades para as codificações, mas sim, orientações de como encaminhar as categorias e conceitos provisórios definidos e organizados na codificação inicial.

Sobre os materiais e ética da pesquisase tratam de materiais como artigos científicos, dissertações e teses, indexadas no Google Acadêmico, resultantes de publicações em Revistas Científicas e Programas de Pós-graduação na área da educação e da psicologia, bem como a fonte na CAPES de dissertações e teses.

A análise dos dados é feita ao mesmo tempo em que são formulados os conceitos, encaminhando as categorias que darão base à teorização, seguindo o método da GT, que engloba a coleta e a análise dos dados para fins de construção da teorização. A análise do material coletado é tanto descritiva, quanto interpretativa, formulando conceitos e unidades de análise, ao mesmo tempo, em que hipóteses são elaboradas pelo pesquisador, para a formulação da teorização.

\section{As unidades categorias (UC)}

O conjunto das SCC, dos dados iniciais e saturados, originaram as UC que são sentenças também, mas com uma característica fundamental: elas agrupam SCC a fim de serem estabelecidas algumas bases para um terceiro grupo de encaminhamento para a configuração da teorização: as unidades conceituais provisórias (UCP).

Criar Educação, Criciúma, v. 6, nº1, janeiro/junho 2017.- PPGE - UNESC 
O Quadro 2 é a apresentação das UC.

Quadro 2. Exemplo de unidades categoriais

\begin{tabular}{|l|l|}
\hline \multicolumn{1}{|c|}{ UNIDADES CATEGORIAIS } & \multicolumn{1}{|c|}{$\begin{array}{c}\text { COD. 2ária. } \\
\text { CORRESPONDENTE }\end{array}$} \\
\hline $\begin{array}{l}\text { Recreação na educação infantil - brincadeiras: gênero e } \\
\text { sexualidade nas práticas pedagógicas. }\end{array}$ & $\begin{array}{l}62.2 .1 ; \\
62.2 .11 ; 62.2 .14\end{array}$ \\
\hline $\begin{array}{l}\text { Ausência da temática da sexualidade nos Projetos } \\
\text { Pedagógicos das escolas de educação infantil }\end{array}$ & 62.2 .2 \\
\hline Sexualidade faz parte sim do desenvolvimento infantil. & $62.2 .3 ; 62.2 .12 ;$ \\
& $62.2 .13 ; 81.21 .3 ;$ \\
81.21 .4
\end{tabular}

Fonte: Silva (2015, p. 125).

A codificação segue o mesmo exemplo das SCC e os fragmentos, assim como as referências bibliográficas estão organizadas no Apêndice da tese (SILVA, 2015).

São estes insights iniciais do pesquisador que permitem o caminhar para a teorização em sexualidade infantil

\section{As unidades conceituais provisórias (UCP)}

Esta etapa, segundo Charmaz (2009, p. 190): “Em vez de deter a análise na etapa da codificação, os pesquisadores podem elevar as suas categorias principais a conceitos".

Elevar categorias à conceitos (teóricos) implica em considerar aquelas categorias que

[..] transportam uma carga analítica substancial. Essas categorias contêm propriedades essenciais que tornam os dados significativos e levam a análise adiante. Decidimos elevar determinada categoria a um conceito em função de aspectos como alcance teórico, caráter incisivo, capacidade para o uso geral e a relação com outras categorias. Elevar categorias a conceitos compreende submetê-las a um novo refinamento analítico e implica a demonstração das suas relações com outros conceitos. [...] Para os construtivistas, os conceitos teóricos servem como estruturas interpretativas e apresentam uma compreensão abstrata das relações. Os conceitos

Criar Educação, Criciúma, v. 6, ำ1, janeiro/junho 2017.- PPGE - UNESC 
teóricos agrupam categorias menores e, em comparação, detêm mais significação, explicam mais dados e normalmente estão mais evidentes. Tomamos uma série de decisões em relação a essas categorias após as termos comparado a outras categorias e aos dados. As nossas ações determinam o processo analítico. Em vez de descobrir uma ordem dentro dos dados, criamos uma explicação, organização e apresentação dos dados [...] (CHARMAZ, 2009, p. 191).

Alguns conceitos que foram organizados na forma de UCP:

- Desenvolvimento biopsicossexossocial. Este conceito, originário nos dados e nas etapas de construção do método da GT evidenciou que todos os textos sobre sexualidade infantil remetem à Freud e à psicanálise. Permitiu a ainda, se propor nesta pesquisa o destaque da sexualidade no desenvolvimento infantil através do sufixo - "ssexo", justamente para não ser mais omitido/escondido sob o termo clássico de desenvolvimento "biopsicossocial". A sexualidade está envolvida no "bio", no "-psico" e no "-ssocial", contudo, se pretende na pesquisa, e é algo que emerge dos dados, que a sexualidade seja explicitada no desenvolvimento infantil.

- Docência-incompletude em sexualidade humana. Um conjunto de dados evidenciou também que os professores (as) se sentem incapazes, sem formação para lidar com as manifestações da sexualidade, presentes, dia a dia, no cotidiano escolar. As formações continuadas são insuficientes e, grande parte dos relatos, indica que, se pudessem, os professores transfeririam a temática dos estudos em sexualidade para profissionais da saúde ou professores de Biologia. A formação em sexualidade humana firma-se, assim, como fio condutor para que a sexualidade infantil seja considerada pelo educador e pela escola num Programa de Educação Sexual formatado no Projeto Pedagógico e esclarecido aos pais, no momento da matrícula.

- Sexualidade infantil nas temáticas sócio-políticas. Foi possível encontrar na pesquisa que a sexualidade infantil é um tema em políticas públicas em educação sexual contra a barbárie e a impunidade no que ser refere à violência e ao abuso sexuais, de crianças e adolescentes. Esta discussão inovadora é de extrema relevância na atualidade.

Estes conceitos permitiram a construção dos memorandos da pesquisa e que encaminham os Relatórios de GT em sexualidade infantil. 


\section{Memorandos}

São organizados três memorandos:

- Memorando 1. A base psicanalítica em sexualidade infantil.

- Memorando 2. Sexualidade infantil e cotidiano escolar.

- Memorando 3. Sexualidade e as temáticas sociais e políticas de proteção à criança: a sexualidade infantil e o espaço escolar.

Os memorandos assumiram a característica de uma produção textual em primeira pessoa, pois são, de fato, conforme propõe a GT, um momento de liberdade do pesquisador em produzir abstrações que são as teorizações, visando uma originalidade que deve configurar o relatório, a teorização em sexualidade infantil.

\section{Relatório Final da GT: a teorização em sexualidade infantil}

Finalmente, chega-se aqui à teorização na forma de três relatórios que se complementam, conforme Quadro 3.

Quadro 3. Os relatórios que compõem a teorização em sexualidade infantil

\begin{tabular}{|l|l|}
\hline \multicolumn{1}{|c|}{ RELATÓRIOS } & \multicolumn{1}{c|}{ ENUNCIADO GERAL } \\
\hline Relatório 1 & $\begin{array}{l}\text { A sexualidade infantil é uma perspectiva de estudo com } \\
\text { foco na teoria psicanalítica sobre a sexualidade em Freud, } \\
\text { mas que traz em seu bojo outras teorias da psicanálise e } \\
\text { autores pós-freudianos até a contemporaneidade (SILVA, } \\
\text { 2015, p. 146). }\end{array}$ \\
\hline Relatório 2 & $\begin{array}{l}\text { A sexualidade infantil na educação escolar deve superar o } \\
\text { silenciamento e a resistência dos atores adultos; deve } \\
\text { superar ações locais de pesquisa e extensão e avançar } \\
\text { para efetividades no PPP, como política esclarecida aos } \\
\text { pais e responsáveis e a toda comunidade escolar (SILVA, } \\
\text { 2015, p. 194). }\end{array}$ \\
\hline Relatório 3 & $\begin{array}{l}\text { Sexualidade infantil e temática político-sociais. Políticas e } \\
\text { gestão da sexualidade visando à proteção da criança }\end{array}$ \\
\hline
\end{tabular}

Criar Educação, Criciúma, v. 6, ํo1, janeiro/junho 2017.- PPGE - UNESC 
Fonte: Silva (2015).

As subseções 2.1.1 a 2.1.4 apresentam, assim, a aplicação do método da GT em uma pesquisa que produziu uma teorização em sexualidade infantil e permitiu o avanço da produção de conhecimento na área da educação sexual no que se refere à constatação de que, tudo que diz respeito à sexualidade infantil, tem seu referencial em Freud e na psicanálise até à contemporaneidade.

\section{Considerações finais}

A partir da questão geral da pesquisa (sua problemática) que procura responder o que é e como se configuraria uma pesquisa no método da GT, gerando produção de conhecimento na área da educação sexual, elenca-se pelo menos, três itens de validação e de legitimidade, que devem estar presentes nas pesquisas em educação sexual, com a utilização da GT e que configuraram a pesquisa de doutoramento aqui exemplificada.

Os itens são os seguintes:

- Item 1: os dados, sejam eles, em documentos, em entrevistas ou participações etnográficas, devem ser altamente suficientes para a construção da teorização, sobretudo e, fundamentalmente, confiáveis, seguindo a rigorosidade do método. Da mesma forma, utilizar o método da GT apenas como análise, sem o percurso definido pelos autores que são referência no método - percurso este seguido na pesquisa aqui apresentada brevemente - implica uma GT parcial e, no mínimo, um pouco superficial e também um pouco fragmentária.

- Item 2: a "libertação" do pesquisador das amarras dedutivas de pesquisa que the permitam abstrair ao máximo; imaginar ao extremo, lançando hipóteses; que the permita conversar "sozinho" com seus dados assim como o químico no laboratório observa as reações químicas e no olhar das transformações traduz as fórmulas e interpreta o que acontece, buscando explicações quanto ao que 
deu certo e o que não deu certo e, depois elabora o seu relatório e, talvez, refaz todo o experimento, para não perder a lógica do processo. Um pesquisador em educação sexual, utilizando-se do método da GT deve estar comprometido com a formulação de conceitos; conceitos que são seus, elaborados por ele e que irão configurar uma teorização que poderá ou não vir a se tornar uma teoria na área do conhecimento.

- Item 3:por último, e mais importante é a questão "utilitária" da teorização organizada. Esta é uma exigência do método. O pesquisador em educação sexual, iniciante e em formação, deve ter em mente, ao longo de todo o percurso da pesquisa, etapa a etapa, que, além de estar coletando dados para serem transformados em teorização, está, definitivamente, comprometido em encontrar nestes mesmos dados, utilidades para a área da educação, da educação sexual, que muitas vezes estarão escondidos, obscuros. É seu dever identificar esta utilidade para a área. Esclarecer a utilidade, deixar explícito. A utilidade da teorização deve ainda indicar: possibilidade de novas pesquisas; aplicabilidades da teorização no aporte empírico e, finalmente, revelar a lacuna que a referida teorização preencheu, na área do conhecimento. Este elemento é fundamental, para se compreender o método da GT e sua perspectiva de produção de generalidades, pois é isto que configura a produção de uma teorização que emerge dos dados.

Vale ainda a consideração: a leitura de uma pesquisa em GT é uma leitura indutiva. Do começo ao fim, uma pesquisa neste método, sugere a atenção às especificidades da produção de conhecimento sob este viés metodológico.

A área da educação sexual pode, portanto, com o método da GT avançar a produção de conhecimento no sentido da construção de conceitos, de teorizações, visando, em longo prazo, teorias; teorias que tenham não somente a arcabouço do discurso, mas, ao seu lado, experiências e vivências em sala de aula com uma atenção á prática pedagógica e a formação de professores, sobretudo, na educação infantil e nos anos iniciais, em que o desenvolvimento infantil biopsicossexossocial é determinante para a formação cidadã emancipatória pautada na diversidade sexual.

\section{Referências}

CHARMAZ, K. A construção da teoria fundamentada. Guia prático para análise qualitativa. Porto Alegre: Artmed, 2009. 
CLARKE, A. E. Discipliningreproduction: modernity, American Life sciences, andtheproblems of sex. Berkeley, CA: UniversityofCalifornia Press, 1998.
CLARKE,
A.
E.
Situationalanalysis

groundedtheorymappingafterthepostmodernturn. Symboliclnteraction, 26, n. 4, p. 553-576, 2003.

CLARKE, A. E. Situationalanalysis: groundedtheoryafterthepostmoderntwn. Thousand Oaks, CA: Sage, 2005.

FRANCO, M. A. S. Pedagogia como ciência da educação. $2^{\underline{a}}$ ed. rev. ampl. São Paulo: Cortez, 2008.

GHEDIN, E. FRANCO, M. A. S. Questões de método na construção da pesquisa em educação. 2ª . ed. São Paulo: Cortez, 2011.

MAIA, A. C. B. RIBEIRO, P.R. M. Educação Sexual: princípios para a ação. Doxa, v. 15, n. .1 , p. 75-84, 2011.

PIMENTA, S. G. O estágio na formação de professores. Unidade teoria e prática? 11ª ed. São Paulo: Cortez, 2012.

SAMPIERI, R.H; COLLADO, C.H; LUCIO, P.B. Metodologia de Pesquisa. $3^{a}$ ed. São Paulo: Mcgraw-Hill, 2006.

SILVA, C.R. Proposta teórico-interpretativa em sexualidade infantil: contribuição à educação sexual a partir da Grounded Theory.2015.Tese. (Doutorado em Educação Escolar) -Programa de Pós-Graduação em Educação, Universidade Estadual Paulista "Júlio de Mesquita Filho", Faculdade de Ciências e Letras, Câmpus de Araraquara, Araraquara, São Paulo, 2015. 
TAROZZI, M. O que é a Grounded Theory?Metodologia de pesquisa e de teoria fundamentada nos dados. Petrópolis, RJ: Vozes, 2011.

VIANNA, A. Panorama da Pesquisa Universitária no Brasil: angústias e proposições. UNESC, Criciúma, v. 5, n.ำ 1, julho/novembro 2015. Criar Educação - PPGE UNESC, p. 1-15. 